\title{
LA APLICACIÓN DE LA MEDIACIÓN EN LA INDIGNIDAD DE SUCEDER EN ESPAÑA*
}

\author{
Salvador Morales Ferrer \\ Ilustre Colegio de Abogados de Alzira (Valencia) España
}

\section{Resumen}

Tras la promulgación de la Ley de mediación en asuntos civiles y mercantiles (Ley 5/2012-jul-6), en nuestro Derecho interno se desarrolló la figura jurídica del mediador. Aunque no es tema del presente estudio, debemos saber que España es un Estado plurilegislativo que, a raíz de la promulgación de la norma en ciertas comunidades autónomas, existe una legislación de mediación determinada. Este trabajo se enfoca en la aplicación de la mediación en la indignidad de suceder, puesto que el causante en vida y los herederos testados e intestados pueden llegar a un acuerdo con la mediación y evitar disputas familiares con los demás coherederos o legitimarios. La mediación es una herramienta para que tanto el causante como los herederos testados e intestados alcancen un acuerdo final, obteniendo el causante las "atenciones debidas" en vida y sus legitimarios o herederos no sean indignos de suceder, ni crearles así, un estigma social. Primero se estudia el concepto de la indignidad de suceder en el Código Civil español, pues para comprender la mediación debe desarrollarse este concepto legal. Segundo, cómo acuden las partes en la indignidad de suceder. Tercero, la indignidad de suceder cuando la persona está en condición de discapacidad intelectual. Cuarto, la posibilidad de que una persona que participa en la mediación sufra un trastorno mental y, por último, se revisa la actuación del mediador en la indignidad de suceder, la extinción de la mediación y el acuerdo final, como elementos indispensables para que surja o no un acuerdo final entre las partes en conflicto.

Palabras clave: Derecho, legislación, familia, Derecho de Familia.

\section{El autor:}

Doctor en Derecho por la Universidad de Valencia, programa doctoral Estudios Jurídicos, Ciencia Política y Criminología. Calificación apto y mención cum laude. Licenciado en Derecho, especialista en Derecho Privado por la Universidad Cardenal Herrera (2005) y magíster propio en Mediación y Gestión Eficiente de Conflictos (2014). Correo electrónico: salvadormf@ono.com

Recibido: 1 de septiembre de 2015; evaluado: 15 de septiembre de 2015; aceptado: 21 de septiembre de 2015.

Artículo resultado de investigación propia. 


\title{
IMPLEMENTATION OF MEDIATION IN THE INDIGNITY OF INHERITING IN SPAIN
}

\author{
Salvador Morales Ferrer \\ Ilustre Colegio de Abogados de Alzira (Valencia) España
}

\begin{abstract}
Following the enactment of Law 5/2012, of July 6. Act of mediation in civil and commercial matters, in our national law to some extent developing the legal concept of mediator, but it is not the subject of this study we know that Spain is a pluri state following the promulgation of the standard in certain Autonomous communities have legislation in particular mediation. But in focusing on this work is the application of mediation in the indignity happen. First for the cause being alive and the heirs tested as intestate not to reach an agreement through mediation because there are usually family disputes, there may be a caregiver of the person with disability can be physical, sensory or mental, with the other heirs or heirs. So, I think that is a good tool mediation to both the deceased and the heirs both tested as intestate find a final agreement for the cause first has the "attention due" in life and later are not unworthy to succeed her heirs or heirs, since these also create them a social stigma. As states, the title of the work is the application of mediation in the indignity to happen in the first chapter the concept of unworthiness to succeed in the Spanish Civil Code is studied, as understanding mediation should develop this legal concept before and in the second chapter as the parties attending the indignity happen. In the third chapter the indignity happen when the person is handicapped intellectually as may be the case in mediation, and the fourth chapter the possibility that a person involved in the mediation suffer a mental disorder is also studied, being able to take this situation in mediation, and finally in the fifth performance of the mediator in the indignity happen, extinction of mediation and final settlement, as essential elements for the emergence or not a final agreement between the parties to the conflict have studied and well the performance of the mediator in this conflict.
\end{abstract}

Keywords: Law, legislation, family, Family Law.

\section{About the author:}

PhD in Law by the University of Valencia, doctoral program in Legal Studies, Political Science and Criminology. Qualified with pass and a cum laude mention. Law B.A., specialized in Private Law by the University Cardenal Herrera (2005) and Masters degree in Mediation and efficient management of conflicts (2014). Email: salvadormf@ono.com

Received: September 1, 2015; reviewed: September 15, 2015; accepted: September 21, 2015. 


\section{La indignidad para suceder}

\subsection{Consideraciones generales}

La doctrina atribuye el inicio de la mediación a la antigua China, como lo aporta Parkinson:

En la antigua China, ya en el siglo V. a, C., Confucio instaba a las personas a usarla en lugar de ir al tribunal, con la advertencia de que la litigación causaba resentimiento en las partes y les impedía cooperar entre sí. Por tanto, recomendaba que, en lugar de pleitear, encontrasen un pacificador neutral que les ayudase a alcanzar un acuerdo. ${ }^{1}$

El concepto de mediación deriva del latín medius-medium, que significa "en medio". Así, las personas mediadoras se sitúan "en medio" del conflicto para ayudar en la comunicación, exploración de opciones y toma de decisiones a las personas que son protagonistas en el acto de mediación. La mediación es un procedimiento consensuado, como afirma Rodríguez:

[...] la mediación, como procedimiento consensuado, a través del cual las partes buscan el acercamiento de sus posiciones con ayuda de un mediador, que interviene para que las partes puedan discutir sus puntos de vista y buscar una solución conjunta al conflicto. ${ }^{2}$

En ocasiones, también puede intervenir otro mediador, aunque lo habitual es que solo intervenga uno.

La mediación se trata de mediar entre ambas partes y como elemento principal para la aplicación de la mediación en la indignidad de suceder en la persona con discapacidad que puede tener una discapacidad y los indignos de suceder pueden ser testados o intestados e incluso que uno de ellos cuide de la persona con discapacidad o no y que existan desavenencias de índole familiar. Entiendo que es de gran relieve la mediación como elemento primero que la persona con discapacidad

Lisa Parkinson, Mediación familiar. Teoría y práctica: principios y estrategias operativas (Barcelona: Gedisa 2005), 23

2 Sonia Rodríguez Llamas, La mediación familiar en España. Fundamento, concepto y modelos jurídicos (Valencia: Tirant lo Blanch, 2010), 97. 
sea bien atendida y segundo elemento que las desavenencias o malos entendidos familiares cesen en el conflicto y, al mismo tiempo, que los indignos de suceder a la persona con discapacidad sean dignos de suceder, pues esto además crea un estigma social para ellos y sus descendientes, por lo que es importante el estudio de la mediación en la indignidad de suceder.

\subsection{El concepto de indigno de suceder en el Código Civil español y sus efectos}

El Artículo 756.7 del Código Civil español señala: "Tratándose de la sucesión de una persona con discapacidad, las personas con derecho a la herencia que no hubieren prestado las atenciones debidas, entendiéndose por tales las reguladas en los artículos 142 y 146 del Código Civil", por lo que tendremos que remitirnos a estos dos Artículos. El Artículo 142 del Código Civil expresa:

Se entiende por alimentos todo lo que es indispensable para el sustento, habitación, vestido y asistencia médica.

Los alimentos comprenden también la educación e instrucción del alimentista mientras sea menor de edad y aún después cuando no haya terminado su formación por causa que no le sea imputable.

Entre los alimentos se incluirán los gastos de embarazo y parto, en cuanto no estén cubiertos de otro modo.

El Artículo 146 de la misma norma indica: "La cuantía de los alimentos será proporcional al caudal o medios de quien da y las necesidades de quien los recibe".

Entre los autores que definen la indignidad para suceder, cabe citar a Pastor Álvarez, que manifiesta:

[...] se configura como causa generadora de incapacidad para suceder abintestato (sin realizar testamento el causante) el no haber prestado al causante las atenciones debidas durante la vida (entendiendo por tales prestaciones que integran el deber de alimentos), y por ello aunque el causahabiente no fueran una de las personas obligadas a prestarlos. ${ }^{3}$

María del Carmen Pastor Álvarez, "Una nueva estrategia legal ante la discapacidad: la protección patrimonial de las personas discapacitadas". Aranzadi Civil, núm. 3 (2004): 2415. 
Existen otras causas de indignidad para suceder en el Artículo 756 del Código Civil, pero debemos centrarnos en esta. Pérez de Vargas diferencia dos elementos en el Artículo 756.7 del Código Civil:

$1^{\circ}$ El elemento subjetivo, por tanto es el carácter voluntarista, por lo que considera que cuando la Ley establece la indignidad, lo que está haciendo es interpretar la presunta voluntad del causante, quien de haber previsto los hechos por el indigno, no le hubiera querido como sucesor [...]

$2^{\circ}$ El elemento objetivo, la conducta del indigno en sí misma. No interesa cuál haya sido la presunta voluntad del causante, sino la voluntad del legislador que por razones de tipo ético, impone al indigno una sanción civil (la pérdida de la herencia o legado). ${ }^{4}$

De acuerdo con Bustos Lago: "Las personas que están obligadas a prestar alimentos, son los llamados a la herencia del discapacitado y no le han prestado las atenciones o cuidados que hubiese requerido", ${ }^{5}$ en esta situación existe la indignidad de suceder.

Por otra parte, pueden ser indignos de suceder del causante los herederos sin testamento, como los testados. Así lo aclara Mignorance:

[...] el derecho a la herencia, se refiere a quienes tienen ese derecho por imposición legal ya sea como herederos forzosos - legitimarios-, ya sea como herederos intestados. Y entendemos incluidos a los herederos testamentarios, porque para saber que estos tienen derecho a la herencia se precisa: a) que el discapacitado tiene que ser atendido haya testado designándolos herederos, y b) que fallezca. ${ }^{6}$

José Pérez de Vargas Muñoz, Protección jurídica patrimonial de las personas con discapacidad (Madrid: La Ley, 2006), 379.

5 José Manuel Bustos Lago, "Código Civil" en Derecho de Sucesiones, legislación, comentarios y jurisprudencia. Aspectos civiles, procesales y fiscales (Cizur Menor: Aranzadi, 2007), 100.

6 María del Carmen Mingorance Gozálvez, "La nueva causa de indignidad para suceder a las personas con discapacidad" en Familia, matrimonio y divorcio en los albores del siglo XXI. Jornadas internacionales sobre las reformas de Derecho de Familia, coord. Fátima Yáñez Vivero, Araceli Donado Vara y María Fernanda Moretón Sanz (Madrid: Idadfe, UNED, El Derecho editores, 2005), 675-676. 


\subsubsection{Causas para que se produzca la indignidad de suceder}

Como bien señala Mignorance: "[...] esto es de entender que no ha cumplido con el 'deber moral' de las atenciones", 7 por lo que existen unas razones morales para los herederos testados o los abintestatos indignos para suceder, que el legislador plasmó en nuestro Código Civil.

Nuestros tribunales contemplan las relaciones subjetivas entre el discapacitado y sus herederos. Cabe mencionar la Sentencia de la Audiencia Provincial León, cuyo fundamento de Derecho cuarto señala: "Otra valoración moral que pueda hacerse de su conducta en relación al cuidado de un pariente consanguíneo próximo (lo que tampoco se puede ponderar con pleno conocimiento al desconocerse las relaciones particulares existentes entre ellos o conflictos que pudieran surgir)". ${ }^{8}$

En este sentido, aunque la doctrina señala el deber "moral" de atender a la persona discapacitada, como elemento que une a la mediación, la Sentencia citada también indica "lo que tampoco se puede ponderar con pleno conocimiento al desconocerse las relaciones particulares existentes entre ellos o conflictos que pudieran surgir", por lo que se entiende que si se realiza la mediación no serían indignos para suceder; por tanto, la situación se resolvería sin mayor dificultad para el causante y para los herederos abintestatos y testados.

\subsubsection{Las diferencias entre discapacitado e incapacitado judicial en la indignidad}

La figura jurídica del tutor o curador tendría prevalencia en la mediación siempre que la persona fuera incapacitada judicial. Serrano García indica: "Tiene que haber un causante discapacitado (no necesariamente incapacitado, aunque puede ocu-

Mingorance Gozálvez, "La nueva causa de indignidad para suceder a las personas con discapacidad", 675.

8 Audiencia Provincial de León, Sentencia de 29 de diciembre, núm. 636/2009 (Sección 1ª), Ponente: Manuel García Prada. JUR 2010/107904. 
rrir incapacitación con discapacidad)" y además manifiesta: "cuando, además de discapacitado, el sujeto está judicialmente incapacitado". ${ }^{10}$

Tendremos que recurrir a una sentencia de incapacitación, como señala el Artículo 199 del Código Civil: "Nadie puede ser declarado incapaz, sino por sentencia judicial".

Por tanto, como sostiene Martín Diz: "Se trataría de un sistema de solución de conflictos totalmente ajeno e independiente al sistema jurisdiccional, debiendo ser alternativo a éste" ${ }^{11}$ Como aclara el autor, la mediación serviría para solucionar el conflicto de la indignidad de suceder y así el causante podría ser atendido por los herederos tanto abintestatos como los testados, sin necesidad de acceder a la justicia.

Al respecto manifiesta Merino Ortiz: "Los conflictos intergeneracionales son los siguientes: 'Situaciones relacionadas con la justicia y la toma de decisiones". ${ }^{12}$ Por esto, ambos elementos están inmersos en la indignidad de suceder y prosigue la autora:

El acelerado envejecimiento de la población que se está viviendo en el mundo actual, marcado con una mayor esperanza de vida. La mediación, como forma pacífica de gestión y resolución de conflictos, se presenta como una herramienta que permitirá a las familias y a sus mayores hacer frente a sus problemas de una manera constructiva y dialogante donde todas las partes tengan su reconocimiento y su presencia. El objetivo es crear un escenario óptimo para la comunicación productiva, donde se genere un clima de confianza que permita maximizar la capacidad de cualquiera de las personas afectadas para participar de manera efectiva.

Se entiende que, en este proceso de mediación, las partes participan de forma voluntaria y libre.

\footnotetext{
"Sra. diagnosticada de Esquizofrenia con intenso deterioro mental de 13 de septiembre de 1991 del Ministerio de Asuntos Sociales por presentar enfermedad mental esquizofrénica residual y alteración de la columna con limitación funcional con escoliosis; declarada incapaz". Audiencia Provincial de Burgos, Sentencia de 6 de junio, núm. 214/2006 (Sección 2a) Ponente: Arabela García Espinosa. JUR 2006/228757, fundamento de Derecho 2.

10 Ignacio Serrano García, Protección patrimonial de las personas con discapacidad. Tratamiento sistemático de la Ley 41/2003 (Madrid: Iustel, 2008), 559.

11 Fermín Martín Diz, La mediación: sistema complementario de la Administración de Justicia (Madrid: Consejo General del Poder Judicial, 2010), 272.

12 Cristina Merino Ortiz, La mediación familiar en situaciones asimétricas. Procesos de gestión de conflictos con episodios de violencia, drogodependencias, enfermedad mental y desequilibrio de poder (Madrid: Instituto Complutense de Mediación y Gestión de Conflictos, 2013), 77-78.
} 


\section{El acudir las partes a la mediación en la incapacidad de suceder}

Puede que las partes abintestato no sean conocedoras del asunto o conflicto que se plantea, bien por su carácter técnico o por la complejidad del mismo. Otro elemento susceptible puede ser que las partes no estén motivadas para asistir a la mediación, como menciona la Sentencia de la Audiencia Provincial de León, en su fundamento de Derecho cuarto: "Otra valoración moral que pueda hacerse de su conducta en relación al cuidado de un pariente consanguíneo próximo (lo que tampoco se puede ponderar con pleno conocimiento al desconocerse las relaciones particulares existentes entre ellos o conflictos que pudieran surgir)". ${ }^{13}$ Una situación adicional sería que las partes tienen unos planteamientos poco reales de la situación legal y pueden ser indignas para suceder.

\subsection{Situaciones familiares}

Puede ocurrir que la relación entre las partes enfrentadas no represente una cuestión de carácter prioritario. Asimismo, si las partes se concienciaran en la búsqueda de la situación, atenderían a la mediación. De esta forma, se entiende que la indignidad de suceder se trata de una cuestión única.

Por otra parte, esta gestión de conflicto de la indignidad de suceder contempla conflictos familiares, por lo que la mediación depende, en parte, de la concepción de familia. Del Campo expresa: "Por definición, una persona que vive sola no es una familia, aunque conserve lazos familiares con sus parientes". ${ }^{14}$ Podemos pensar que las personas indignas para suceder son primos hermanos del causante y no tienen buenas relaciones; si desea, alguno de ellos puede ir a mediación e inclusive el causante en vida puede sugerirlo.

A efectos hereditarios, Méndez Valdivia ${ }^{15}$ entiende que:

13 Audiencia Provincial de León, Sentencia de 29 de diciembre.

14 Salustiano del Campo, "Las transiciones de la familia española". Abor Consejo Superior CLXXVIII, núm. 702 (junio 2004): 457. arbor.revistas.csic.es/index.php/arbor/article/download/575/577 (acceso octubre 11, 2014).

15 María Teresa Méndez Valdivia, "La mediación en conflictos familiares relacionados con personas mayores en situación de dependencia" en Aportaciones de la mediación en el marco de la prevención gestión y solución de conflictos familiares, ed. Rocío López San Luis (Granada: Comares, 2011), 81. 
La intervención en conflictos de familia en los que la demanda de mediación se expresaba la preocupación sobre la herencia ha supuesto el 6,6\%. Entendemos conveniente aclarar que los acuerdos que toman las familias relacionados con este aspecto son, posteriormente, tramitados en notaría si así lo han establecido en acuerdo.

Aunque la autora habla de los herederos testados, se asume que también es aplicable a los intestados, puesto que pueden llegar a un acuerdo final en prestar las "atenciones debidas" al causante en vida y así no ser indignos de suceder.

\subsection{Aspectos parentales}

Tenemos que ver el parentesco entre las personas que acuden a la mediación, como aporta Méndez Valdivia:

Las personas que acuden a la mediación se observa que mayoritariamente tienen un vínculo de madre, padre con hijo o hija. El hecho de que venga un padre o madre para tratar asuntos con su hijo o hija es, en muchas ocasiones, una situación de postruptura de pareja con dificultad relacional". ${ }^{16}$

No solo es la posterior ruptura de la pareja con dificultad relacional, sino que también pueden acudir en la mediación de la indignidad de suceder primos hermanos o incluso los herederos testados que, aun sin ser consanguíneos, pueden ser herederos testados. Este sería el caso del causante que nombra herederas a dos personas sin vínculo sanguíneo y luego se desentienden de la persona y esta, a su vez, adquiere una discapacidad reconocida, sea física o sensorial; a todo esto, los herederos testados no contemplan las "atenciones debidas" al causante por motivos personales o porque no tienen buena relación, por lo que tanto el causante como los herederos testados pueden acudir a la mediación:

1. Para que los herederos testados presten al causante las "atenciones debidas".

2. Para que los testados que sean declarados indignos puedan sean herederos.

Méndez Valdivia, "La mediación en conflictos familiares relacionados con personas mayores en situación de dependencia", 83-84. 
Por otro lado, tenemos a los herederos abintestatos (que el causante no hubiera realizado testamento) que sí pueden ser consanguíneos, puesto que pueden ser hijos e hijas, hermanos, primos hermanos e incluso su cónyuge, que no presten las "atenciones debidas" a la persona con discapacidad. La mediación es una herramienta para que no se aplique el Artículo 756.7 del Código Civil y no sean declarados indignos de suceder.

Méndez Valdivia afirma:

Las personas acuden a la premediación con un ánimo de informarse para trasladar al resto de protagonistas esta posibilidad. A partir de esta sesión informativa, si todos los implicados aceptan, se desarrolla el proceso específico para cada conflicto y familia. ${ }^{17}$

En este caso, puede ocurrir que existan varios coherederos y que uno de ellos se haga cargo del causante y decida acudir la mediación con la articulación de los pasos previstos en ella. A todo esto, no se puede descartar que un heredero abintestato atienda al causante e inste a los demás coherederos a acudir a la mediación.

Parkinson expresa:

En primer lugar puede ser necesario consultar con un médico sobre la conveniencia de la mediación. En el caso afirmativo, la persona discapacitada puede necesitar un apoyo físico y emocional cual será el papel del que proporcione este apoyo y el grado en que él o ella puedan actuar como portavoz, para resolver una disputa específica o para elaborar una decisión consensual sobre su cuidado en el futuro. ${ }^{18}$

Lo que expresa la autora no es que solo se declaren indignos para suceder a la persona discapacitada, sino que además le presten las "atenciones debidas" en vida los herederos testados y abintestatos.

A modo de conclusión, por las siguientes causas, es muy interesante la aplicación de la mediación en la indignidad de suceder:

Méndez Valdivia, "La mediación en conflictos familiares relacionados con personas mayores en situación de dependencia", 83.

18 Parkinson, Mediación familiar, 294. 
1. No ser declarado indigno de suceder.

2. Si existen varios coherederos que atiendan a la persona con discapacidad "las atenciones debidas".

3. Los elementos que desencadenan para acudir a la mediación.

Merino Ortiz sostiene:

La planificación y toma de decisiones respecto a la mejor forma de vivir el proceso inevitable de envejecimiento; es decir, ajustando la forma de llevar a cabo de manera independiente las funciones habituales de la vida a la pérdida gradual o repentina de la capacidad para realizarlas. En este tipo de conflictos está más íntimamente ligado a la salud de la persona mayor que puede valerse por sí misma o estar en situación de dependencia y añade los asuntos que se pueden tratar:

1) Disputas familiares sobre el cuidado de la persona mayor.

2) Discusiones entre la persona anciana y sus familiares sobre la forma en que va a vivir.

3) Conflictos por incumplimiento de la medicación.

4) Conflictos con personas cuidadoras o el personal que asiste a la persona anciana.

Y finalmente en el contexto patrimonial:

5) Conflictos sobre sucesiones. ${ }^{19}$

Aunque trato la mediación en las personas con discapacidad, la indignidad de suceder también es aplicable a una persona anciana.

\section{La indignidad de suceder cuando la persona están en condición de discapacidad intelectual}

Debemos atender al Artículo 199 del Código Civil, que define: "Nadie puede ser declarado incapaz, si no es por sentencia judicial en virtud de las causas establecidas por la Ley" y en la misma norma cabe señalar el Artículo 200, que indica: "Son causas de incapacitación las enfermedades o deficiencias persistentes de carácter físico o psíquico que impidan a la persona gobernase por sí misma".

19 Merino Ortiz, La mediación familiar en situaciones asimétricas, 154-155. 
En esta situación podemos encontrar que la persona discapacitada tuviese tutor o curador puesto como afirma la doctrina, entre otros, De Cossio, ${ }^{20}$ que entiende: "[...] se trata por tanto, de un acto judicial que modifica el estado civil de una persona", por lo que existen distintas formas para la figura jurídica del tutor o curador sea destituido de su cargo, situación en la que no voy a entrar, puesto que el presente trabajo trata sobre la mediación.

\subsection{Situaciones de incapacidad en la mediación}

Bolás manifiesta:

[...] el incapaz no discapacitado judicialmente se encuentra protegido únicamente por sus padres, parientes o familiares, que de buena fe, pero claramente equivocados, no promueven la incapacitación por considerarla algo "vergonzosa" y por entender que un no discapacitado está mejor integrado en la sociedad que un discapacitado, expresando los ejemplos las personas que están sufriendo el inicio de una enfermedad degenerativa (Alzheimer) o que han sufrido un súbito derrame cerebral, del que pueden recuperarse, el caso de las personas que sufren drogodependencia que llevan a la ruina a su familia, considerándolas a estas personas que carecen de status legal, como sin papeles. ${ }^{21}$

Por tanto, en este último caso, Méndez Valdivia entiende que:

[...] la persona que demanda en primer lugar la mediación posiblemente está asumiendo los cuidados de la persona con alguna discapacidad o considera que esa posible dependencia se va a agudizar en un plazo de tiempo breve y ya no puede hacerse responsables en las mismas condiciones de atención que habían tenido hasta entonces. ${ }^{22}$

Entonces, el guardador de hecho de la persona sería quien tiene que iniciar la mediación si existieran otros coherederos, pues estos serían indignos de suceder a la persona discapacitada no incapacitada judicialmente. Puede suceder que una persona

20 Alfonso de Cossio y Corral, Instituciones de Derecho Civil. Parte general: obligaciones y contratos, Tomo I, 2a ed. (Madrid: Civitas, 1991), 80.

21 Juan Bolás Alfonso, "Inauguración del seminario" en La protección jurídica de los discapacitados, incapaces y personas en situaciones especiales, dir. Rafael Martínez Die (Madrid: Civitas, 2000), 22.

22 Méndez Valdivia, "La mediación en conflictos familiares relacionados con personas mayores en situación de dependencia", 83. 
discapacitada no incapacitada judicialmente sea cuidada por un primo hermano y tenga otros dos primos hermanos; el primero puede acudir a la mediación para que los restantes coherederos no sean indignos de suceder, solo si estos la aceptan, puesto que es voluntaria. A todo esto se pronuncia la Jurisprudencia en la Sentencia de Primera Instancia de Málaga, cuyo fundamento de Derecho segundo señala:

Pero sobre todo esa obligatoriedad "reforzada" vendría dada porque estaríamos ante negocios jurídicos de familia cuya elaboración se desarrolla en un entorno especialmente apto para que la expresión de la voluntad allí recogida lo haga sin vicio alguno, pues se desarrolla por la intervención técnica del mediador, la voluntariedad de la participación, la igualdad en el desarrollo de los debates que llevan al consenso e incluso la posibilidad de contar con información y asesoramiento suficiente..$^{23}$

\section{La posibilidad de que una persona que participa en la mediación sufra un trastorno mental}

Como hemos visto, los coherederos o el causante pueden acudir a la mediación y especialmente a la premediación para informarse.

\subsection{Las crisis en la persona que participa en la mediación}

Pueden considerarse frecuentes, porque son una reacción adaptativa en la propia crisis familiar. Sin embargo, no siempre existe un diagnóstico que determine cuál es el grado de salud mental de cada persona para decidir y responsabilizarse de los acuerdos alcanzados en la mediación. Por tanto, en la mediación deben intervenir equipos de formación multidisciplinar, que faciliten la detección y gestión de situaciones que puedan surgir en el proceso y canalicen hacia una derivación a tratamiento terapéutico. Cabe aclarar que la remisión a otra entidad profesional no supone la necesaria finalización del proceso. En ciertas ocasiones, ante determinados trastornos diagnosticados, se puede actuar con representantes o apoyo familiar, con la posibilidad de interrumpir temporalmente el proceso y continuar una vez recuperado el equilibrio emocional. Sobre la formación multidisciplinar de la mediación se pronuncia la jurisprudencia cuando señala:

\footnotetext{
Sentencia Primera Instancia de Málaga, Sentencia núm. 5 de 27 septiembre 661/2012. AC/2012/1920, Ponente: José Luis Utrera Gutiérrez.
} 
[...] es importante resaltar que en la práctica de la mediación en conflictos familiares los mediadores, aun cuando posean una formación específica respecto a las instituciones jurídicas objeto de negociación, su función no es asesorar (tarea reservada a los abogados de las partes). De hecho pueden proceder de otras licenciaturas o disciplinas, y no obstante ser excelentes profesionales que pueden ayudar a las partes a alcanzar acuerdos muy positivos para sus vidas. ${ }^{24}$

Los comportamientos identificados con especial complejidad pueden surgir en cualquiera de las partes protagonistas del conflicto de mediación.

A mi modo de ver, esta enumeración de situaciones es abierta y requiere su contextualización e individualización del proceso, en el sentido de que en algunas ocasiones se tendrá que recurrir a la coordinación con equipos profesionales que, desde otras entidades públicas o privadas, estén bajo tratamiento con la misma familia.

Por otra parte, una de las preocupaciones frente a la mediación en estos casos se refiere a la plena capacidad de estas personas para comunicar y negociar, por lo que puede interrumpirse el proceso de mediación hasta que la persona supere su situación personal.

\section{La actuación del mediador en la indignidad de suceder, extinción de la mediación y acuerdo final}

Ante todo, se debe de tener presente que es una persona con discapacidad, puesto que puede ser su discapacidad física, sensorial o psíquica, por lo que el mediador deberá ser consciente de sus discapacidades y alguna de las partes o incluso todas ellas pueden tener algún tipo de odio o rencor, pues si una de las partes cuida a la persona con discapacidad las otras partes pueden sentirse menos o nada favorecidas, bien por el trato personal o vivencial que han tenido con el causante.

Ares de Giordano señala: "La formalidad en la que se ha refugiado el derecho aparece como insuficiente. Hay que encontrar nuevos procedimientos, más simples y expeditivos, que permitan recrear la confianza, la cooperación, la misma seguridad". ${ }^{25}$

24 Audiencia Provincial de Barcelona, Sentencia de 21 defebrero, núm. 132/2007 (Sección12ª), Ponente: Pascual Ortuño Muñoz JUR 2007/204550.

25 Consuelo Ares de Giordano, Mediación, conflictos y soluciones razonables (Mendoza: Ediciones Jurídicas Cuyo, 2004), 62-63. 
La autora refuerza la aplicabilidad del mediador en la indignidad de suceder y, al mismo tiempo, recuerda que las personas que acuden a él piensan, de modo equivocado, que es como el abogado.

\subsection{La actuación del mediador en la indignidad de suceder}

Las partes deben buscar al mediador y no el mediador a las partes, como bien lo especifica Torrero: "El agente mediador no está obligado a buscar a nadie, son los mismos sujetos interesados, quienes deben buscar al agente mediador familiar". ${ }^{26}$ Otro elemento a destacar es lo que expresan Villagrasa y Vall Rius, ${ }^{27}$ que aportan: "consideran como objetivos fundamentales 'facilitar las vías de diálogo' y la 'búsqueda en común de una solución voluntaria, aceptable y duradera", aunque la autora García ${ }^{28}$ que los cita entiende el objetivo de "facilitar las vías de diálogo, podría identificarse con la ayuda a las partes a 'desempantanarse"' de sus posiciones, pues conseguido esto, aquellas podrán dialogar. En efecto, el mediador actuará para aclarar el conflicto y el método será la facilitación de la vía del diálogo entre las partes en este sentido el causante discapacitado y los herederos testados e intestados para las "atenciones debidas" de este.

El mediador debe ser neutral, imparcial, respetuoso de las partes, empático y flexible, por lo que será un hábil comunicador y facilitador del diálogo, persuasivo y lleno de fuerza, capaz de una escucha activa, creativo, respetuoso, íntegro y ético, capaz de conseguir o de ganar el acceso a los recursos, con sentido del humor, paciente, perseverante, optimista. ${ }^{29}$

\footnotetext{
Magdalena Torrero Muñoz, Las crisis familiares en la jurisprudencia. Criterios para una mediación familiar (Valencia: Práctica del Derecho, 1999), 27.

27 Ana María Vall Rius y Carlos Vilagrasa Alcaide, "La mediación familiar: una nueva vía para gestionar los conflictos familiares", Revista jurídica española de doctrina, jurisprudencia y bibliografía, núm. 3(2000): 1793-1804

28 Lucía García, Mediación familiar: prevención y alternativas al litigio en los conflictos familiares (Madrid: Dikinson, 2003), 57.

29 Parkinson enuncia los principios de la mediación, que son: " 1 Participación voluntaria (preceptiva en algunos países); $2^{\circ}$ Imparcialidad del mediador (a veces dominada "neutralidad"); $3^{\circ}$ Revelación de cualquier conflicto de intereses por parte del mediador; $4^{\circ}$ Fortalecimiento de la capacidad de los participantes para tomar sus propias decisiones con suficiente información (en inglés "empowerment"); $5^{\circ}$ Respeto de los individuos y de la diversidad cultural; $6^{\circ}$ Seguridad personal y protección frente al riesgo; $7^{\circ}$ Confidencialidad sujeta a ciertos límites; $8^{\circ}$ Legalidad privilegiada; $9^{\circ}$ Enfocada al futuro y no al pasado; $10^{\circ}$ Énfasis en los intereses mutuos en lugar; $11^{\circ}$ Consideración de las necesidades de todos los interesados; $11^{\circ}$ Competencia del mediador". Parkinson, Mediación familiar, 29-30.
} 
1. Neutralidad. Un mediador no debe tener preferencias personales para que la disputa no se resuelva en la línea de sus preferencias. Está para ayudar a ambas partes, tanto al causante como a los herederos testados y no testados.

2. Imparcialidad. El mediador no obtiene ningún beneficio por el proceso ni por los resultados, más allá de los honorarios pactados. Además, no puede relacionarse con las partes por fuera de la mediación, no obtener ventajas para algunas de las partes o estimular a las partes a considerar términos de un acuerdo que involucran ganancia para el mediador.

3. Respeto por las partes. El mediador debe ser capaz de manejar el proceso, respetar y hacer respetar la confidencialidad. Bernal ${ }^{30}$ aporta el concepto de confidencialidad:

El mediador mantendrá toda la información relativa al proceso de mediación bajo estricta confidencialidad, incluso el hecho de si el proceso se está llevando a cabo o ya ha tenido lugar. Cualquier tipo de información transmitida a los mediadores por una de las partes, no podrá ser revelada a la otra parte sin el consentimiento de la primera, a no ser que la ley la obligue.

Asimismo, deberá decidir si es necesario separar a las partes en las reuniones privadas (caucus) y asistir a las partes sin asumir protagonismo.

4. Empatía y flexibilidad. Estas características le permiten promover y no retardar la fluidez de las discusiones. Debe tener criterio y aprovechar las oportunidades que surjan para el beneficio de las partes. Por ejemplo, si surge una proposición que permite llegar a una salida positiva, el mediador debe tomarla y no argumentar que está fuera de la agenda. Además, debe ser inteligente y trabajar cualquier asunto que se presente sobre la mesa de trabajo y que permita el avance positivo y constructivo de la negociación. La capacidad de empatía del mediador da a las partes confianza en las soluciones alternativas que están explorando no van a ignorar sus necesidades.

5. Habilidad comunicativa y facilitación del diálogo. Las partes en disputa suelen tener claro lo que desean, pero no tanto lo que buscan. En general, comienzan

30 Trinidad Bernal Samper, La mediación: una solución a los conflictos de ruptura de pareja, 4a ed. (Madrid: Colex, 2008), 118 . 
la mediación aclarando lo que no quieren, sin poder concretar lo que sí aspiran a conseguir.

Por otro lado, puede ocurrir que no comprendan lo que otros dicen; el mediador debe aclarar situaciones y transmitir ideas, enunciar, ante todo focalizar en el presente y el futuro, trabajar las emociones y convicciones de las partes y crear un puente para que se comprendan mutuamente.

El mediador no solo debe tomar en cuenta no solo aquello que la gente dice de forma explícita, sino también lo que subyace en su discurso y lo que las partes comunican de modo indirecto. Puede hacer una lectura de ambas partes, a partir de su historia, su cultura y sus necesidades.

También es preciso que el mediador entre en el conflicto con pocos conocimientos previos y aprenda de las partes de qué se trata la situación y cómo es vivida e interpretada por cada una de ellas, porque si tuviera conocimientos anteriores, se causarían perjuicios en el funcionamiento de la mediación. Por lo que se entiende que cada parte tiene la razón y espera que el mediador apoye y ayude a resolver el conflicto a su favor.

A veces, las partes no pueden llegar a un acuerdo a causa del lenguaje que se usa y tiene que ver con dudas, temores y otras respuestas negativas. Por ello, se utilizarán las técnicas como reenmarcar o retitular una situación, para posibilitar que las partes acepten trabajar en conjunto bajo esos términos.

En ocasiones, el mediador debe traducir las proposiciones a un lenguaje que incremente la probabilidad de que sean recibidas favorablemente, pero sin mentir. Tiene la responsabilidad primaria de estructurar y conducir las discusiones, para que se consigan soluciones aceptables.

6. Persuasión y fortaleza. El mediador debe de ser un apasionado por su trabajo, creer en el proceso de mediación y trasmitirlo a las partes. Por tanto, debe tener la fuerza suficiente para convencer a los disputantes de que sean razonables y flexibles y saber sortear las que llevan a acrecentar la disputa.

7. Escucha activa. El mediador debe escuchar y comprender las preocupaciones, los intereses y los deseos de las partes. Si está todo el tiempo hablando 
y preguntando, las partes pueden pensar que no está interesado en ver sus problemas como ellos los ven.

La escucha activa se relaciona con la intención puesta por el mediador en entender a las partes y mostrarles que les presta atención. Esto se logra al establecer contacto visual con las partes cuando estas hablan, al aclarar lo que van diciendo, al retroalimentar y al mostrar un sincero interés en lo que cada parte afirma. El punto básico de la escucha activa es atender y exponer lo que se ha entendido.

8. Creatividad. El mediador actuará para ayudar a las partes a desarrollar la creatividad y hará sus aportes para obtener un resultado positivo, constrictivo y centrado en el futuro.

9. Respeto, integridad y ética. El mediador debe ser honorable y capaz y su presencia no debe constituir un insulto a las partes; por el contrario, las partes deben sentir orgullo de ser asistidas por el mediador, porque lo considera una persona de bien. Por tanto, las partes, en este caso causante e indignos de suceder, tienen un conflicto y necesitan ser ayudadas por el mediador que confían y cuyos antecedentes o reputación (la presentación del mediador a las partes) permiten tener la confianza necesaria para revelarle, con sinceridad, sus necesidades y preocupaciones, puesto que las partes no confían la una en la otra, es imprescindible que puedan confiar en el mediador.

10. Capacidad de conseguir acceso a los recursos. Este punto va unido al anterior. Se requiere que el mediador tenga autoridad moral y esté habilitado para obtener con prontitud los recursos necesarios para resolver la disputa.

11. Sentido de humor. El mediador debe tener habilidad para reírse de sí mismo. El uso del humor puede ayudar a bajar las tensiones entre las partes; eso sí, debe ser respetuoso y constructivo. Siempre debe tener presente que las cuestiones dichas con humor pueden relacionarse con prejuicios, honor, credibilidad, honradez, etc., puesto que las partes pondrían en duda la credibilidad del mediador y el mismo proceso.

12. Paciencia. El mediador no puede forzar un acuerdo entre las partes. Como es lógico, este debe de estar preparado para tomarse el tiempo necesario para escuchar las preocupaciones de las partes y, si es necesario, asistirlos en la resolución de sus diferencias. El proceso de mediación no es lineal; no siempre 
avanza hacia la solución y muchas veces puede no ir bien. En este momento, la paciencia es precisa para continuar el proceso.

13. Perseverancia. Es una característica del mediador su capacidad de perseverar frente a las continuas dificultades que implica el abordaje del conflicto. Esto no implica repetir los intentos, sino variar sus métodos, de acuerdo con los cambios y la situación.

14. Optimista. El mediador debe tener una visión positiva y optimista de los eventos que enfrenta en la mediación. Debe transmitir a las partes confianza en que los problemas pueden resolverse, si esto es así y ayudar a que las partes asuman su protagonismo y se hagan cargo de la situación del conflicto. El mediador debe ser realista en el optimismo y evaluar con la posibilidad del éxito las partes.

Por el contrario, si el mediador transmite su optimismo con poca importancia, las partes no tendrán interés en resolver; por ello, el mediador debe ser optimista, pero no paternalista. Esto significa que no debe hacerse cargo del conflicto, porque este es de las partes.

\subsection{Los distintos estadios del mediador en la indignidad de suceder}

Romero aporta los estadios del mediador desde su responsabilidad:

En los primeros momentos de la mediación, el mediador se encarga de fijar el tono emocional del proceso, a continuación explica las metas y los propósitos del proceso, así como su papel, refuerza la competencia y responsabilidad de las partes y propone que la meta es construir un camino donde el foco estará centrado en el futuro y no en el pasado, y posteriormente recoge datos sobre la motivación actual y sus estilos de interacción y comunicación. Valora los antecedentes inmediatos y los eventos precipitantes del conflicto atendiendo a la historia del conflicto. Balancea la comunicación, impidiendo que cada parte hable demasiado tiempo seguido y redefine las posturas de manera positiva. Separa las dimensiones intra e interpersonales del conflicto proporcionando a los participantes un lugar seguro para dejar a parte sus defensas personales y sacar a flote los temas encubiertos. Evita términos demasiado legales, permitiendo a las partes utilizar su propio lenguaje. El mediador ha dejado claro 
que no tomará decisiones, pero que será responsable del control del proceso, enfatiza las áreas de acuerdo preexistentes, y facilita la búsqueda de acuerdos en temas sencillos, pidiendo a las partes planes para conseguir los objetivos fijados, éste promueve la identificación y delimitación de las alternativas que aparecen como más viables.

Al respecto, el cliente debe sentir que el mediador entiende los aspectos críticos y la dinámica de las relaciones familiares. El mediador puede orientar sobre algunas metas específicas del proceso, promoviendo el conocimiento personal sobre conflictos internos o encubiertos que fluyen en el proceso, reducir el efecto de ciertas frustraciones afectivas o respuestas emocionales, como las conductas que interfieren en la solución del conflicto. El proceso se impulsa si se limita o detiene actitudes autoritarias e intimidantes verbales creándose una estructura de poder más igualitaria entre los participantes en las sesiones.

Por otro lado, el mediador ayuda a los participantes a evitar el regateo posicional y a utilizar un estilo más blando buscando qué opción es la que mejor responde a las necesidades de todos, éste facilita la toma de decisiones. Actúa como agente de la realidad, y finalmente el mediador refuerza la conducta cooperativa y el progreso realizado, y escribe o facilita la escritura de los acuerdos. Dando copia a las partes.

Por otro lado, si no hay acuerdo, el mediador refuerza los esfuerzos que han llevado a cabo y ofrece la posibilidad de retomar el diálogo en otro momento en que éste resulte más viable. ${ }^{31}$

El mediador debe actuar de esta forma tanto en la mediación que trato como en todas las formas de mediación y utilizar las técnicas que hemos estudiado.

\subsection{La extinción de la mediación en la indignidad de suceder}

Puede darse la extinción del contrato de mediación, como afirma Torrero:

31 Fermín Romero Navarro, La mediación una visión plural. Diversos campos de aplicación (Las Palmas de Gran Canaria: Consejería de Presidencia y Justicia Viceconsejería de la Justicia y Seguridad Gobierno de Canarias, 2005), 78-80. 
Las principales causas de extinción son las siguientes: 1. Por el transcurso del tiempo fijado por las partes; $2^{\text {a }}$ Por voluntad de cualquiera de las partes actoras del conflicto si se evidencia la imposibilidad de lograr el acuerdo; $3^{\circ}$ Por acuerdo de mediación suscrito entre las partes, al haberse obtenido la finalidad propuesta; 4. Por voluntad del agente mediador, cuando considera que es imposible la mediación. De darse esta situación, necesariamente deberá comunicárselo a las partes para que éstas sean libres de iniciar o continuar los procesos correspondientes. ${ }^{32}$

Por tanto, la autora indica la extinción de la mediación, pues como en todos los ámbitos, incluso en el mundo del Derecho, todo puede dar sus frutos o no puede darlos.

\subsection{El acuerdo final en la mediación}

El acuerdo de mediación será suscrito entre las partes actoras del conflicto, con el fin de que no deban acudir al órgano judicial y tendrá efecto obligacional, como cualquier otro contrato.

García sostiene: "Es, en definitiva, una concreción del principio general de la autonomía privada consagrado en el artículo 1255 del Código Civil". ${ }^{33}$ De esta forma, el Artículo 1255 del Código Civil indica: "Los contratantes pueden establecer los pactos, cláusulas y condiciones que tengan conveniente, siempre que no sean contrarios a las leyes, a la moral, ni al orden público". Como señala la autora, el citado Artículo es el pilar de la mediación.

¿Cómo puede ser oponible frente a terceros el acuerdo de mediación? Su oposición será mediante los fedatarios públicos, que son los notarios, para que los transcriban en los correspondientes documentos públicos para su posterior inscripción en el Registro Público pertinente.

Torrero Muñoz, Las crisis familiares en la jurisprudencia, 33-34.

García García, Mediación familiar, 57. 


\section{Conclusiones}

1. En nuestro ordenamiento jurídico interno, en el Código Civil en su Artículo 756.7, es de aplicabilidad la mediación respecto al causante y sus legitimarios que son los herederos testados como los intestados, aunque el legislador no percibiera su aplicación.

2. La mediación favorece al causante en el momento en el que las partes lleguen al acuerdo final. El causante tendrá las "atenciones debidas" de los legitimarios tanto testados como intestados.

3. La aplicación en la indignidad de suceder será voluntaria y libre, tanto para el causante en vida como para los indignos que, llevados al conflicto, dejarán de serlo.

4. La aplicación de la mediación en la indignidad de suceder es favorable, porque no se llega a los juzgados y, además, es más rápida que declarar a los herederos testados como intestados indignos de suceder.

5. El mediador actúa entre las partes en la mediación, puesto que estos tienen un conflicto con el causante y sus herederos tanto testados como intestados.

6. El mediador debe tener en cuenta que pueden surgir problemas con alguna parte, lo que implica la paralización del conflicto y su posterior reanudación, si la parte recupera su estabilidad psíquica.

7. En la mediación se debe atender al contexto cultural y al lenguaje de las partes.

8. Cuando las partes van a la mediación, creen que el mediador actuará como un abogado para resolver su conflicto, pero son ellos quienes deben resolverlo.

9. El mediador debe actuar si lo es no como un abogado, puesto que actúa como mediador y su labor es asesorar y mantener los postulados que indica la Ley de mediación y la doctrina, para no sancionarlo.

10. La mediación puede tener un acuerdo satisfactorio para las partes en conflicto, como no lo puede tener de ahí la causa de extinción. 


\section{Referencias}

Ares de Giordano, Consuelo. Mediación, conflictos y soluciones razonables. Mendoza: Ediciones Jurídicas Cuyo, 2004.

Audiencia Provincial de Barcelona. Sentencia núm. 132/2007 de 21 de febrero, (Sección12a). Ponente: Pascual Ortuño Muñoz JUR 2007/204550.

Audiencia Provincial de Burgos. Sentencia núm. 214/2006 de 6 de junio (Sección 2aa). Ponente: Arabela García Espinosa. JUR 2006/228757.

Audiencia Provincial de León. Sentencia núm. 636/2009 de 29 de diciembre (Sección 1ª). Ponente: Manuel García Prada. JUR 2010/107904.

Bernal Samper, Trinidad. La mediación: una solución a los conflictos de ruptura de pareja. 4a ed. Madrid: Colex, 2008.

Bolás Alfonso, Juan. "Inauguración del seminario" en La protección jurídica de los discapacitados, incapaces y personas en situaciones especiales, dirigido por Rafael Martínez Die. Madrid: Civitas, 2000.

Bustos Lago, José Manuel. "Código Civil" en Derecho de Sucesiones, legislación, comentarios y jurisprudencia. Aspectos civiles, procesales y fiscales. Cizur Menor: Aranzadi, 2007.

De Cossio y Corral, Alfonso. Instituciones de Derecho Civil. Parte general: obligaciones y contratos. Tomo I. 2a ed. Madrid: Civitas, 1991.

Del Campo, Salustiano. "Las transiciones de la familia española". Abor Consejo Superior CLXXVIII, núm. 702 (junio 2004): 451-464. arbor.revistas.csic.es/index.php/arbor/ article/download/575/577 (acceso octubre 11, 2014).

García, Lucía. Mediación familiar: prevención y alternativas al litigio en los conflictos familiares. Madrid: Dikinson, 2003.

Martín Diz, Fernando. La mediación: sistema complementario de la Administración de Justicia. Madrid: Consejo General del Poder Judicial, 2010.

Méndez Valdivia, María Teresa. "La mediación en conflictos familiares relacionados con personas mayores en situación de dependencia" en Aportaciones de la mediación en el marco de la prevención gestión y solución de conflictos familiares, editado por Rocío López San Luis, 73-86. Granada: Comares, 2011.

Merino Ortiz, Cristina. La mediación familiar en situaciones asimétricas. Procesos de gestión de conflictos con episodios de violencia, drogodependencias, enfermedad mental y desequilibrio de poder. Madrid: Instituto Complutense de Mediación y Gestión de Conflictos, 2013.

Mingorance Gozálvez, María del Carmen. "La nueva causa de indignidad para suceder a las personas con discapacidad" en Familia, matrimonio y divorcio en los albores del siglo 
XXI. Jornadas internacionales sobre las reformas de Derecho de Familia, coordinado por Fátima Yáñez Vivero, Araceli Donado Vara y María Fernanda Moretón Sanz, 673-678. Madrid: Idadfe, UNED, El Derecho editores, 2005.

Parkinson, Lisa. Mediación familiar. Teoría y práctica: principios y estrategias operativas. Barcelona: Gedisa, 2005.

Pastor Álvarez, María del Carmen. "Una nueva estrategia legal ante la discapacidad: la protección patrimonial de las personas discapacitadas". Aranzadi Civil, núm. 3 (2004): 2423-2444.

Pérez de Vargas Muñoz, José. Protección jurídica patrimonial de las personas con discapacidad. Madrid: La Ley, 2006.

Rodríguez Llamas, Sonia. La mediación familiar en España. Fundamento, concepto y modelos jurídicos. Valencia: Tirant lo Blanch, 2010.

Romero Navarro, Fermín. La mediación una visión plural. Diversos campos de aplicación. Las Palmas de Gran Canaria: Consejería de Presidencia y Justicia Viceconsejería de la Justicia y Seguridad Gobierno de Canarias, 2005.

Sentencia Primera Instancia. de Málaga. Sentencia núm. 5 de 27 septiembre 661/2012. AC/2012/1920. Ponente: José Luis Utrera Gutiérrez.

Serrano García, Ignacio. Protección patrimonial de las personas con discapacidad. Tratamiento sistemático de la Ley 41/2003. Madrid: Iustel, 2008.

Torrero Muñoz, Magdalena. Las crisis familiares en la jurisprudencia. Criterios para una mediación familiar. Valencia: Práctica del Derecho, 1999.

Vall Rius, Ana María y Carlos Vilagrasa Alcaide. "La mediación familiar: una nueva vía para gestionar los conflictos familiares". Revista jurídica española de doctrina, jurisprudencia y bibliografía, núm. 3(2000): 1793-1804. 